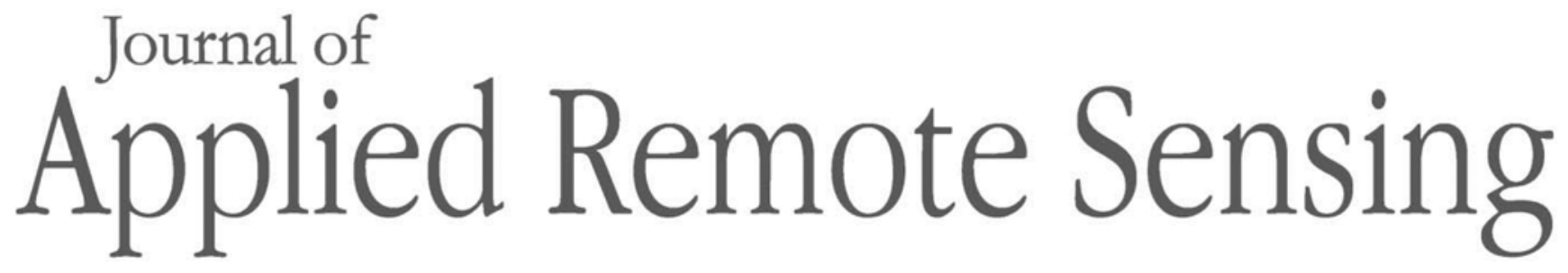

RemoteSensing.SPIEDigitalLibrary.org

\title{
Optically thin midlevel ice clouds derived from Cloud Aerosol Lidar and Infrared Pathfinder Satellite Observations
}

Vinay K. Kayetha
Richard L. Collins 


\title{
Optically thin midlevel ice clouds derived from Cloud Aerosol Lidar and Infrared Pathfinder Satellite Observations
}

\author{
Vinay K. Kayetha and Richard L. Collins* \\ University of Alaska Fairbanks, Geophysical Institute and Department of Atmospheric Sciences, \\ 903 Koyukuk Drive, Fairbanks, Alaska 99775-7320, United States
}

\begin{abstract}
We use measurements from the Cloud Aerosol Lidar and Infrared Pathfinder Satellite Observation (CALIPSO) to identify optically thin midlevel ice clouds and determine their occurrence and properties. We identify these clouds as having cloud top heights between $2 \mathrm{~km}$ above the ground and the tropopause plus $1 \mathrm{~km}$, cloud base temperatures less than $-10^{\circ} \mathrm{C}$, and cloud top temperatures greater than $-38^{\circ} \mathrm{C}$. Globally, we find that these clouds occur at least $5 \%$ of the time and represent $7 \%$ of all tropospheric clouds detected by CALIPSO at a horizontal scale of $10 \mathrm{~km}$. The cloud type fraction decreases with increasing horizontal scale, representing $4 \%$ of clouds at $25 \mathrm{~km}, 2 \%$ at $50 \mathrm{~km}$, and less than $0.1 \%$ at $100 \mathrm{~km}$. These clouds occur most commonly in the Arctic, most often in winter and least often in summer. During the winter, these clouds occur up to $15 \%$ of the time in the Arctic. We found five large $(\sim 500 \mathrm{~km})$ distinct clouds over the Arctic and investigated their meteorological conditions and radiative effects. We find that these thin midlevel ice clouds have a warming effect on the surface from 23 to $48 \mathrm{~W} / \mathrm{m}^{2}$. Our study highlights the importance of active satellite-based remote sensing in globally detecting and characterizing optically thin clouds. (0) The Authors. Published by SPIE under a Creative Commons Attribution 3.0 Unported License. Distribution or reproduction of this work in whole or in part requires full attribution of the original publication, including its DOI. [DOI: 10.1117/1.JRS.10.046007]
\end{abstract}

Keywords: midlevel clouds; optically thin ice clouds; radiative transfer; Cloud Aerosol Lidar and Infrared Pathfinder Satellite Observation.

Paper 16493 received Jul. 1, 2016; accepted for publication Oct. 3, 2016; published online Oct. 24, 2016.

\section{Introduction}

Fundamental questions on the climate system remain unanswered because of our limited understanding of how clouds, atmospheric circulation, and climate interact. From a climate perspective, it is important to understand clouds and their radiative effects. Clouds play a critical role in regulating the Earth's energy budget by reflecting the incoming solar radiation and trapping the outgoing thermal radiation. The radiative effects of clouds depend on their macrophysical (altitude, temperature, and geometrical thickness) and microphysical (particle phase and size distribution) properties. ${ }^{1-3}$ Despite their importance, the accurate representation of cloud types in global/regional climate models remains a challenge. The present work focuses on midlevel clouds. According to the World Meteorological Organization, midlevel clouds are those that typically form in the Earth's atmosphere with their base altitudes at 2 and $7 \mathrm{~km}$ above the surface level. ${ }^{4,5}$ Surface observations and passive satellite measurements show that midlevel clouds cover up to $22 \%$ of the Earth's surface. ${ }^{6-8}$ Midlevel clouds have been documented by several field campaigns in the tropics (e.g., Refs. 9-11), midlatitudes (e.g., Refs. 12-14), and polar regions (e.g., Refs. 15-17). However, our understanding of midlevel cloud processes and their representation in models remains poor. Studies show that almost all operational global climate models underestimate midlevel cloud occurrences. ${ }^{18,19}$ One of the challenges in observing midlevel clouds is that when observed remotely from the surface or top of the atmosphere,

*Address all correspondence to: Richard L. Collins, E-mail: rlcollins@alaska.edu 
they are often obscured by low- or high-level clouds. Furthermore, the range of temperatures in the middle troposphere (where ice, liquid, or both phases can exist) makes the determination of the cloud properties more difficult. There are commonly two types of midlevel clouds according to the "genera" of cloud classification: ${ }^{5}$ altostratus and altocumulus. In general, altostratus clouds are ice dominated and altocumulus clouds are water dominated. ${ }^{20}$ Altostratus clouds form as thick and dark layers, sufficient to partially or totally block the disk of sun or moon for a surface observer. Altocumulus clouds form as cellular structures and are relatively thin often with ice virga precipitating from the cloud base. Although these traditional midlevel clouds are optically thick, several studies indicate they can also exist as optically thin clouds. ${ }^{18,20,21}$ Such optically thin altostratus and altocumulus clouds are least studied because of the detection limitations of both ground-based measurements and satellite passive sensors.

Recent advances in satellite active remote sensing have supported new studies of these cloud types. Several studies have used the combination of radar and lidar aboard the Cloudsat and Cloud Aerosol Lidar and Infrared Pathfinder Satellite Observation (CALIPSO) satellites to study midlevel clouds. ${ }^{22,23}$ The distribution and phase partition of liquid-layer topped midlevel clouds, which is a typical characteristic of traditional altocumulus type of clouds, has been reported. ${ }^{22}$ The global distribution of altostratus and altocumulus clouds has been reported. ${ }^{23}$ In this study, we focus exclusively on optically thin midlevel ice clouds as measured by the lidar onboard the CALIPSO satellite. We present the occurrence of these clouds in the context of the low-, mid-, and high-level clouds that are detected by CALIPSO. We report the seasonal and global distribution of these clouds. We determine their radiative impact in the Arctic, where these clouds are observed most commonly.

\section{Data Set and Methodology}

\subsection{CALIPSO Data Set}

The payload of CALIPSO satellite consists of three coaligned, near-nadir viewing instruments: a dual-wavelength Cloud Aerosol Lidar with Orthogonal Polarization (CALIOP), an imaging infrared radiometer, and a high-resolution wide-field camera. ${ }^{24}$ The CALIOP uses an Nd:YAG laser that transmits pulses at both 532- and 1064-nm wavelengths, with pulse energy of $110 \mathrm{~mJ}$, and a pulse length of $20 \mathrm{~ns}$. The lidar pulse repetition at the rate of $20.16 \mathrm{~Hz}$ allows for a sampling of complete atmospheric column every $\sim 333 \mathrm{~m}$ on the ground. To reduce the bandwidth of the downlinked data, the resolution of the data decreases with altitude. The vertical and horizontal resolutions of the downlinked data are 30 and $333 \mathrm{~m}$ between the ground and $8.2 \mathrm{~km}$, 60, and $1000 \mathrm{~m}$ between 8.2 and $20.2 \mathrm{~km}$, respectively. The CALIOP measurements are calibrated and geolocated to produce attenuated backscattering profiles that are made available to users as level-1 data product. Feature detection algorithms and cloud properties retrieval techniques are applied to the level-1 attenuated backscatter profiles to yield level-2 cloud data products.

We use four years (December 1, 2006 to November 30, 2010) of CALIOP measurements in this study. We use the 5-km cloud layer data product (i.e., CAL_LID_L2_05kmCLay-Prov-V3), which provides information on all clouds detected from various horizontal signal-averaging schemes. The CALIPSO feature detection algorithm uses several resolutions (i.e., 5, 20, and $80 \mathrm{~km})$ and signal averaging to increase the signal-to-noise ratio of the measurements and detect even, thin clouds and aerosol layers in the atmosphere. ${ }^{25}$ All the clouds that are detected are provided in the 5-km data product along with the horizontal averaging used in identifying those clouds.

\subsection{Cloud Classification Algorithm}

We summarize our cloud classification algorithm in Fig. 1. We first limit our attention to tropospheric clouds. Our algorithm employs a maximum allowable cloud top height as $1 \mathrm{~km}$ above the local tropopause level to avoid the inclusion of stratospheric clouds. We used a maximum allowable height of $12 \mathrm{~km}$ for the regions poleward of $60^{\circ} \mathrm{N}$ and $60^{\circ} \mathrm{S}$ as the tropopause altitude is often ambiguous in the polar regions. We then identify all clouds with cloud top altitudes less 


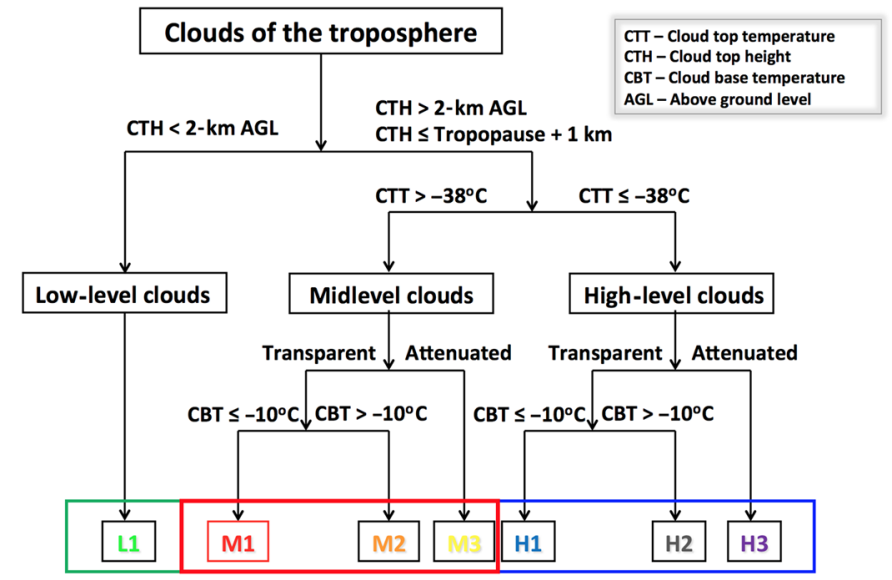

Fig. 1 Logic-based rules used to categorize tropospheric clouds detected by CALIPSO.

than $2 \mathrm{~km}$ above the ground as low-level clouds (L). We classify the clouds with top altitudes greater than $2 \mathrm{~km}$ of the ground level into six distinct types based on the cloud top temperature, cloud base temperatures, and optical depth. We classify the clouds with top temperature above $-38^{\circ} \mathrm{C}$ as midlevel clouds (M) and below $-38^{\circ} \mathrm{C}$ as high-level (H, i.e., cirrus) clouds. Studies show that as the cloud temperature falls below $-38^{\circ} \mathrm{C}$ supercooled liquid droplets freeze homogeneously to initiate the formation of ice particles. ${ }^{26-28}$ We use the transparency flags of the cloud layers provided by the CALIPSO data product to classify the clouds as attenuated or transparent. The CALIOP data processing algorithm characterizes the identified cloud layers as either attenuated or transparent and calculates the optical depth of transparent (i.e., optically thin) clouds with visible optical depths less than 3 to $4 .{ }^{29}$ Finally, we use the cloud base temperature of $-10^{\circ} \mathrm{C}$ to distinguish between ice- and water-dominated clouds. Studies have shown that clouds have a minimum ice particle concentration of 1000 particles $/ \mathrm{m}$ at temperatures less than $-10^{\circ} \mathrm{C} .{ }^{30}$ Using these rules, we categorize all the tropospheric clouds into seven types (i.e., L1, M1, M2, M3, H1, H2, and H3). We present these categories of tropospheric clouds with their descriptions in Table 1. The M1 clouds are the ice dominated optically thin midlevel clouds that are the primary focus of this study.

We show an example of our cloud classification scheme on CALIPSO data segment drawn from over both northern and southern hemispheres in Fig. 2. Figure 2(a) shows CALIPSO measurements on December 27, 2006, over the Arctic Ocean from Bathurst Island $\left(75^{\circ} \mathrm{N}, 99^{\circ} \mathrm{W}\right)$ to the New Siberian Islands $\left(75^{\circ} \mathrm{N}, 143^{\circ} \mathrm{E}\right)$. We detect six of our seven cloud types (i.e., L1, M1, M2, M3, H1, and H3). Several layers of optically thin high-level clouds (H1) and optically thin

Table 1 Description of cloud types based on logic-based rules.

\begin{tabular}{lll}
\hline \hline Type & \multicolumn{1}{c}{ Cloud-phase } & \multicolumn{1}{c}{ Description } \\
\hline L1 & $\begin{array}{l}\text { Water, } \\
\text { mixed-phase, ice }\end{array}$ & $\begin{array}{l}\text { Cumulus, stratus, and stratocumulus clouds. All low-lying ice clouds, } \\
\text { specifically over the polar regions }\end{array}$ \\
M1 & Ice, mixed-phase & Optically thin altostratus and altocumulus clouds that are ice dominated \\
M2 & Mixed-phase, water & Optically thin altostratus and altocumulus clouds that are water dominated \\
M3 & Mixed-phase, water & $\begin{array}{l}\text { Altostratus, altocumulus, and nimbostratus clouds } \\
\text { H1 }\end{array}$ \\
Ice & $\begin{array}{l}\text { Mixed-phase, } \\
\text { water, ice }\end{array}$ & $\begin{array}{l}\text { Optically thin cirrus clouds } \\
\text { (warm temperatures) }\end{array}$ \\
H3 & Ice, mixed-phase & $\begin{array}{l}\text { Optically thick clouds with ice particles at the top altitudes, } \\
\text { such as cumulonimbus clouds }\end{array}$ \\
\hline \hline
\end{tabular}




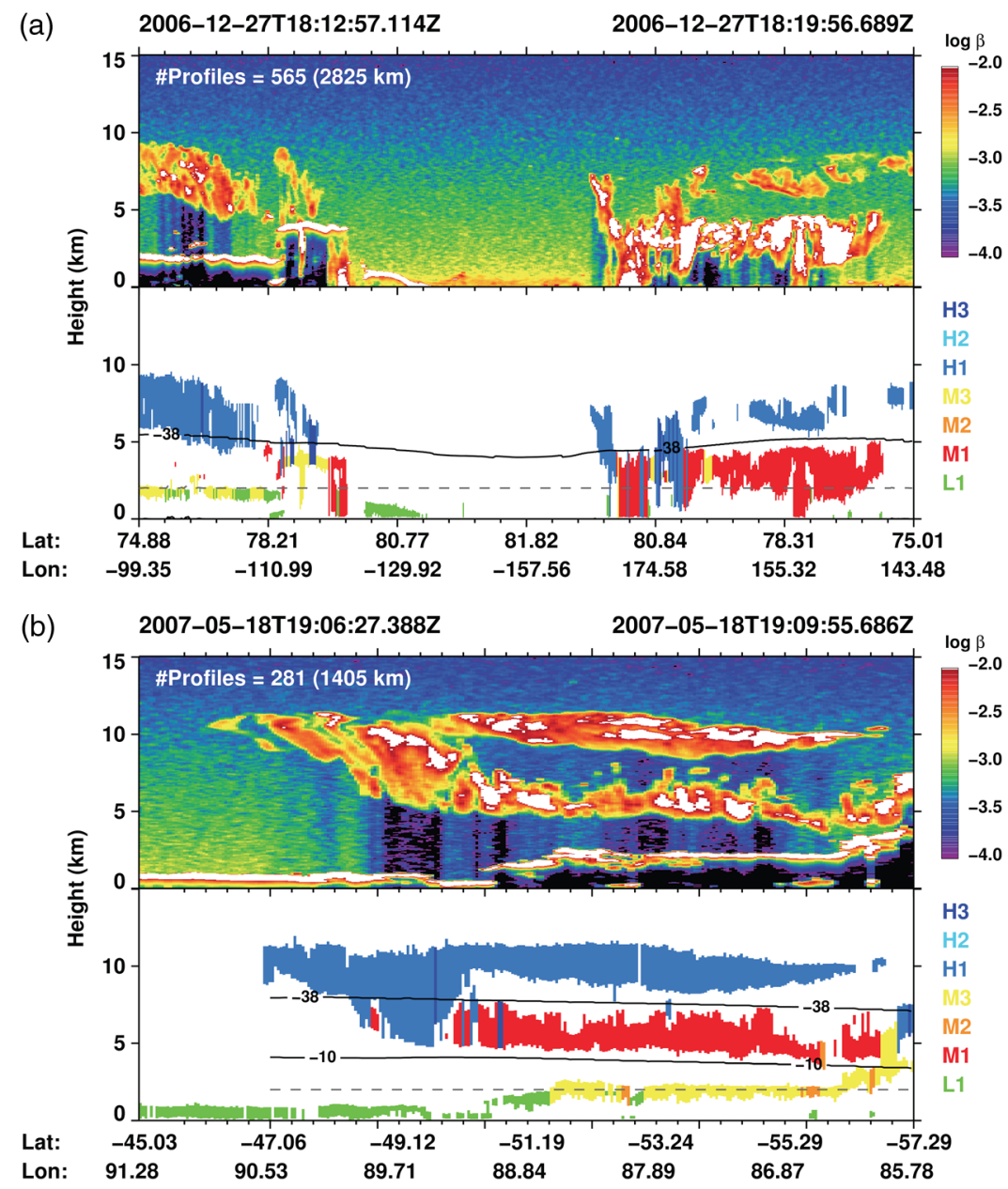

Fig. 2 (Upper) CALIPSO backscattering (lower) and cloud type derived from our logic-based rules from an overpass (a) over the Arctic region on December 27, 2006 and (b) over the Southern Ocean on May 18, 2007. The dotted line indicates the 2-km altitude level above the surface. The temperature contours at $-10^{\circ} \mathrm{C}$ and $-38^{\circ} \mathrm{C}$ are also plotted.

midlevel clouds (M1) dominate the clouds in this observation. The M1 cloud observed over the New Siberian Islands $\left(75^{\circ} \mathrm{N}, 143^{\circ} \mathrm{E}\right)$ spans a horizontal scale of $135 \mathrm{~km}$ (27 profiles). In Fig. 2(a), the temperature remains less than $-10^{\circ} \mathrm{C}$ at the surface, thus there is no contour plotted at $-10^{\circ} \mathrm{C}$. Figure 2(b) shows CALIPSO measurements on May 18, 2007, over the Southern Ocean $\left(45^{\circ} \mathrm{S}\right.$, $91^{\circ} \mathrm{E}$ to $57^{\circ} \mathrm{S}, 85^{\circ} \mathrm{E}$ ). This example clearly illustrates the occurrence of optically thin midlevel ice cloud, where the lidar signals could penetrate through the cloud and detect a cloud layer lying below. The M1 cloud observed here spans a horizontal scale of $110 \mathrm{~km}$ (22 profiles).

Having first classified all tropospheric clouds into seven types, we investigate the horizontal scale of the clouds using a continuity analysis. We conclude that a cloud has a scale of $n$ profiles if a given cloud type is present at the same altitude over $n$ successive profiles. We choose $n$ as 2 , $5,10,20$, and 100 corresponding to $10,25,50,100$, and $500 \mathrm{~km}$, respectively. The use of continuity over increasing numbers of successive profiles not only provides information on the spatial scales of the cloud, but also eliminates isolated cloudy profiles from the sample (e.g., M2 and $\mathrm{H} 3$ in Fig. 2). After counting the total number of valid clouds in each type, we calculate the frequency of occurrence and fraction of clouds based on the total observations (profiles) divided by the value of $n$. We then bin the types of clouds obtained from the entire data set into a $2.5^{\circ} \times 5^{\circ}$ latitude-longitude grid. We derive cloud statistics for an average of four years of binned data. We define the frequency of occurrence of a cloud type as the number of cloudy profiles to the total number of profiles (clear plus cloudy). We define the cloud type fraction for a given cloud type as the ratio of the number of clouds identified as that particular type to the total number of clouds identified. 
Kayetha and Collins: Optically thin midlevel ice clouds derived from Cloud Aerosol Lidar...

Table 2 Cloud detection statistics for CALIPSO observations at 10-km scale.

\begin{tabular}{lccc}
\hline \hline Type & Number of clouds & Frequency of clouds (\%) & Cloud type fraction (\%) \\
\hline H1 & $12,520,659$ & 17 & 28 \\
H2 & 27,994 & $<0.1$ & $<0.1$ \\
H3 & $5,141,715$ & 7 & 11 \\
M1 & $3,371,498$ & 5 & 4 \\
M2 & $1,728,463$ & 2 & 21 \\
M3 & $9,713,249$ & 13 & 28 \\
L1 & $12,825,372$ & 17 & \\
1: Total profiles $=74,739,836$ & & \\
2: Total number of valid clouds $=45,328,950$ & & \\
\hline \hline
\end{tabular}

\section{Results}

\subsection{Global Distribution of Tropospheric Clouds}

We first investigate the CALIPSO observations at 1-profile resolution or a 5-km spatial scale. Over the four-year period, there were 149.5 million profiles, where clouds are absent in 46.0 million profiles. This indicates that $31 \%$ of the Earth's surface is under clear skies, while $69 \%$ is cloudy. In the cloudy profiles, $28 \%$ of the clouds are low-level clouds (L1), $36 \%$ are midlevel clouds (M1, M2, and M3), and 36\% are high-level clouds (H1, H2, and H3). We find that these results are insensitive to changes of $\pm 2^{\circ} \mathrm{C}$ in the cloud top and cloud base temperature thresholds of our classification scheme. In summary, we find that M1 clouds have the following characteristics, optical depths between 0.1 and 6.0 with a mean optical depth of 0.8 , cloud top heights between 2.0 and $12.0 \mathrm{~km}$ with mean height of $6.0 \mathrm{~km}$, cloud top temperatures between $-38^{\circ} \mathrm{C}$ and $-10^{\circ} \mathrm{C}$ with a mean temperature of $-27^{\circ} \mathrm{C}$, cloud base heights between 0.1 and $11.3 \mathrm{~km}$ with a mean height of $4.7 \mathrm{~km}$, and cloud base temperatures between $-37^{\circ} \mathrm{C}$ and $-10^{\circ} \mathrm{C}$ with a mean temperature of $-21^{\circ} \mathrm{C}$.

As seen in Fig. 2, clouds of one type can be found as single profiles embedded in a larger cloud of another type (e.g., M2 in M1). We assume this may reflect a classification error. We thus present our results based on the CALIPSO observations at 2-profile resolution or a 10-km spatial scale. We tabulate the frequency of occurrence and the fraction of clouds for each category from the four years (December 1, 2006 to November 30, 2010) in Table 2. Over these four years, the total number of profiles is divided by two and amounts to 74.7 million profiles. We find a total of 45.3 million valid cloudy profiles, indicating a global cloud cover of $61 \%$ for clouds of a horizontal size of $10 \mathrm{~km}$ or greater.

We present the global distribution of cloud frequency of occurrence and fraction at 2-profile resolution in Fig. 3. The observations show that L1 and $\mathrm{H} 1$ clouds (low-level and cold thin cirrus clouds) occur most commonly and represent the highest fraction of the cloud types. The L1 clouds occur more commonly over oceans than land. The lower occurrence of L1 clouds over Southern and South East Asia might be due to the presence of H3 or M3 clouds (thick high-level and midlevel clouds) that prevent the detection of underlying L1 clouds. M1 clouds (cold thin midlevel clouds) form most commonly in the extratropics. In the northern hemisphere, the M1 clouds represent a larger fraction of the clouds over land than ocean, which reflects the increased occurrence of L1 clouds over the oceans. M2 clouds (warm thin midlevel clouds) primarily occur in the tropics. M3 clouds (thick midlevel clouds) occur more commonly over ocean than land and extend into the polar regions over the North Atlantic and Southern Oceans. H1 clouds (cold thin cirrus clouds) are found primarily in the tropics and also over Antarctica. The detection of cirrus clouds over the Antarctic may reflect the formation of 


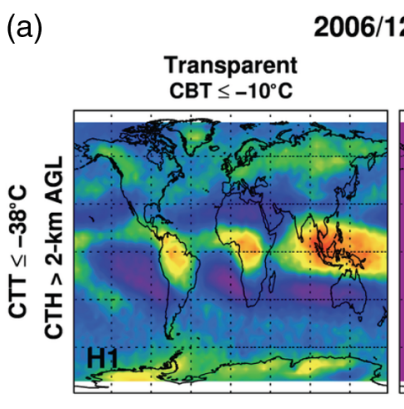

2006/12 - 2010/11, Day \& Night (2prf)
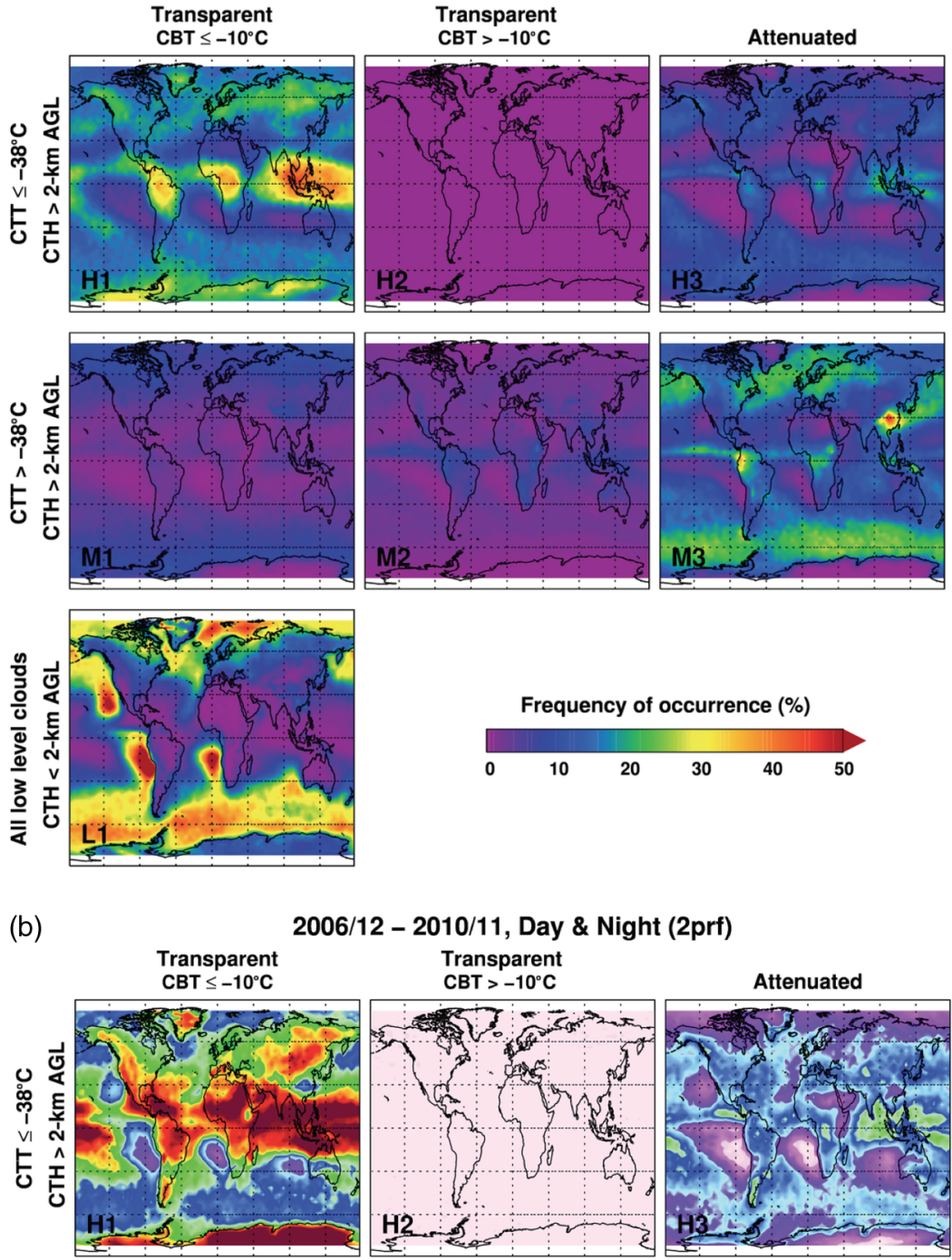

006/12 - 2010/11, Day \& Night (2prf)
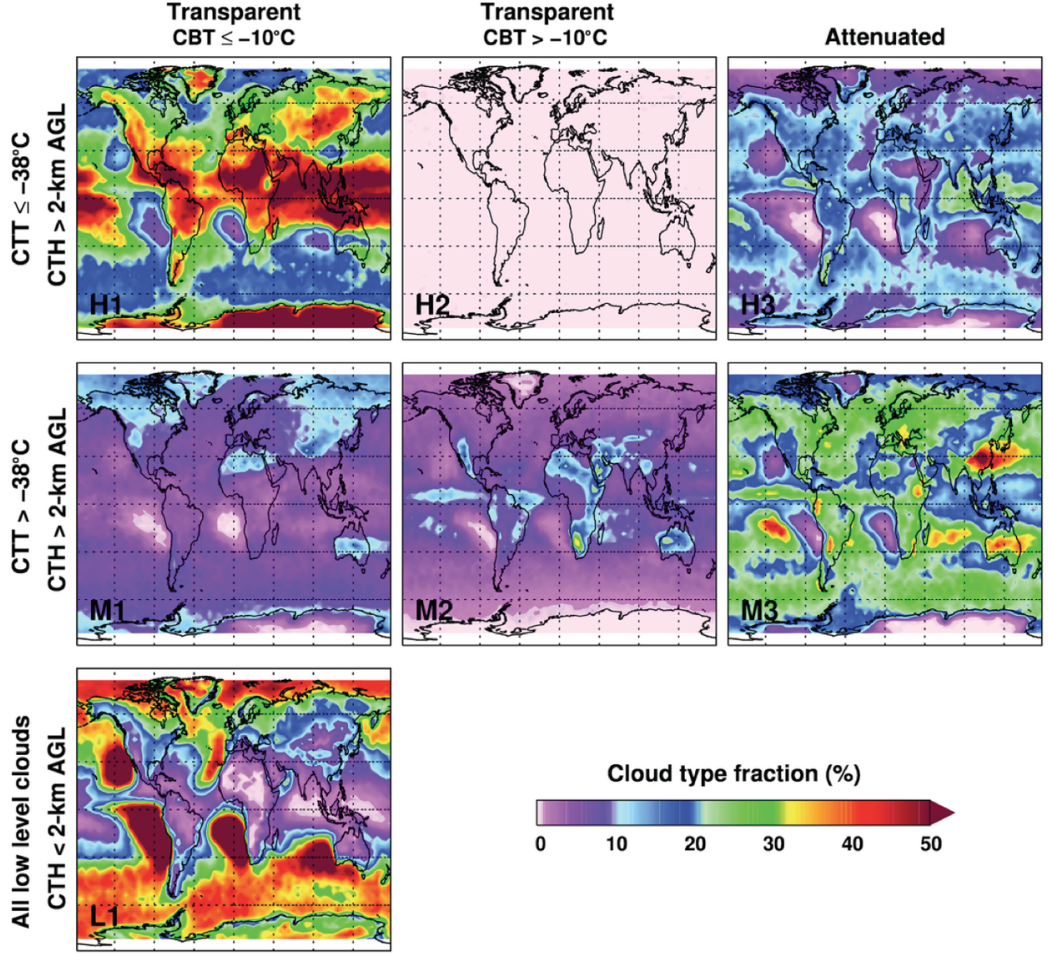

Fig. 3 Global (a) cloud frequency of occurrence and (b) cloud type fraction derived from CALIPSO observations at $10-\mathrm{km}$ resolution.

polar stratospheric clouds that extend into the upper troposphere. H2 clouds (warm thin cirrus clouds) are largely nonexistent. H3 clouds (optically thick high-altitude clouds) are most common in the tropics, least common in the subtropics, and also form in the midlatitudes and polar regions. 


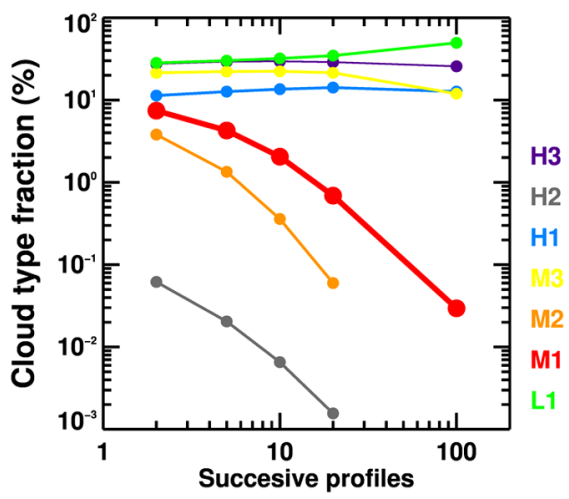

Fig. 4 Global mean fraction of clouds derived from CALIPSO observations plotted as a function of horizontal spatial scale. 1 profile corresponds to $5 \mathrm{~km}$.

\subsection{Spatial Scales of Clouds}

We have determined the number of clouds present at different scales in the CALIPSO data set by detecting clouds that are continuous over increasing larger scales. The total number of clouds detected decreases with increasing scale from $4.53 \times 10^{7}$ clouds at 2-profile $(10 \mathrm{~km})$ resolution to $1.15 \times 10^{6}$ clouds at 20 -profile $(100 \mathrm{~km})$ resolution to $1.70 \times 10^{4}$ clouds at 100 -profile $(500 \mathrm{~km})$ resolution. The global mean fraction of clouds derived from CALIPSO observations at different spatial scales is shown in Fig. 4. We see that with increasing spatial scale, the relative fraction of the different cloud types changes. The global mean fraction of clouds for L1 clouds is found to increase from $\sim 30 \%$ at $10 \mathrm{~km}$ to $\sim 50 \%$ at $500 \mathrm{~km}$. The fraction for $\mathrm{H} 1$ and $\mathrm{H} 3$ clouds is found to stay relatively constant at $\sim 10 \%$ and $\sim 30 \%$, respectively. The fraction of midlevel clouds decreases with increasing spatial scales. The fraction of M3 clouds decreases less rapidly, from $\sim 20 \%$ at $10 \mathrm{~km}$ to $\sim 10 \%$ at $500 \mathrm{~km}$, than the fraction of M1 and M2 clouds. For M1 clouds, the fraction of clouds is $7.4 \%, 4.2 \%, 2.0 \%$, and $<0.1 \%$ at 2-profile $(10 \mathrm{~km}), 5$-profile $(25 \mathrm{~km}), 10$ profile $(50 \mathrm{~km})$, and 20 -profile $(100 \mathrm{~km})$ resolution, respectively. At the largest spatial scale of $500 \mathrm{~km}$, we find only five M1 clouds in this four-year data set. These five clouds are found in the Arctic. We will use these five large M1 clouds later to investigate the radiative effects of M1 clouds.

\subsection{Seasonal and Geographic Distributions of M1 Thin Midlevel Ice Clouds}

We show the seasonal variations in M1 cloud occurrence and cloud type fraction in Fig. 5. These thin midlevel ice clouds occur up to $15 \%$ over the polar regions and extend into the midlatitudes. M1 clouds occur most commonly during the northern winter [December, January, February (DJF)] and least during the northern summer [June, July, August (JJA)], in both hemispheres with an exception of the two high-altitude regions of Greenland and Tibet. These clouds appear along the midlatitude storm tracks in all seasons but are quite low in northern summer (JJA). No seasonal symmetry in M1 cloud occurrences is observed. M1 clouds occur most commonly over both the Arctic and the Southern Ocean during northern winter (DJF) indicating that M1 clouds form through a variety of processes. Over the tropics, M1 cloud occurrences are found to be minimum $(5 \%)$ and are concentrated along the convergence zone, resembling the altocumulus cloud distribution. ${ }^{31}$ The fraction of clouds clearly shows that M1 clouds are more abundant in the northern hemisphere than in the southern hemisphere. This may be related to the availability of ice nuclei for the formation of M1 clouds. Studies have shown that dust particles from the arid regions act as effective ice nuclei. ${ }^{32,33}$ The occurrence of high fraction of M1 clouds over arid regions in Africa, Asia, and Australia supports the assertion that such nucleation processes contribute to the formation of M1 clouds. In the northern hemisphere, M1 clouds are most common along the western Arctic extending into the midlatitudes and less common in the synoptically active North Pacific and Atlantic Oceans, where cloud droplets grow to large sizes and produce precipitation. Over the southern hemisphere, M1 clouds are found over the oceans surrounding Antarctica. 

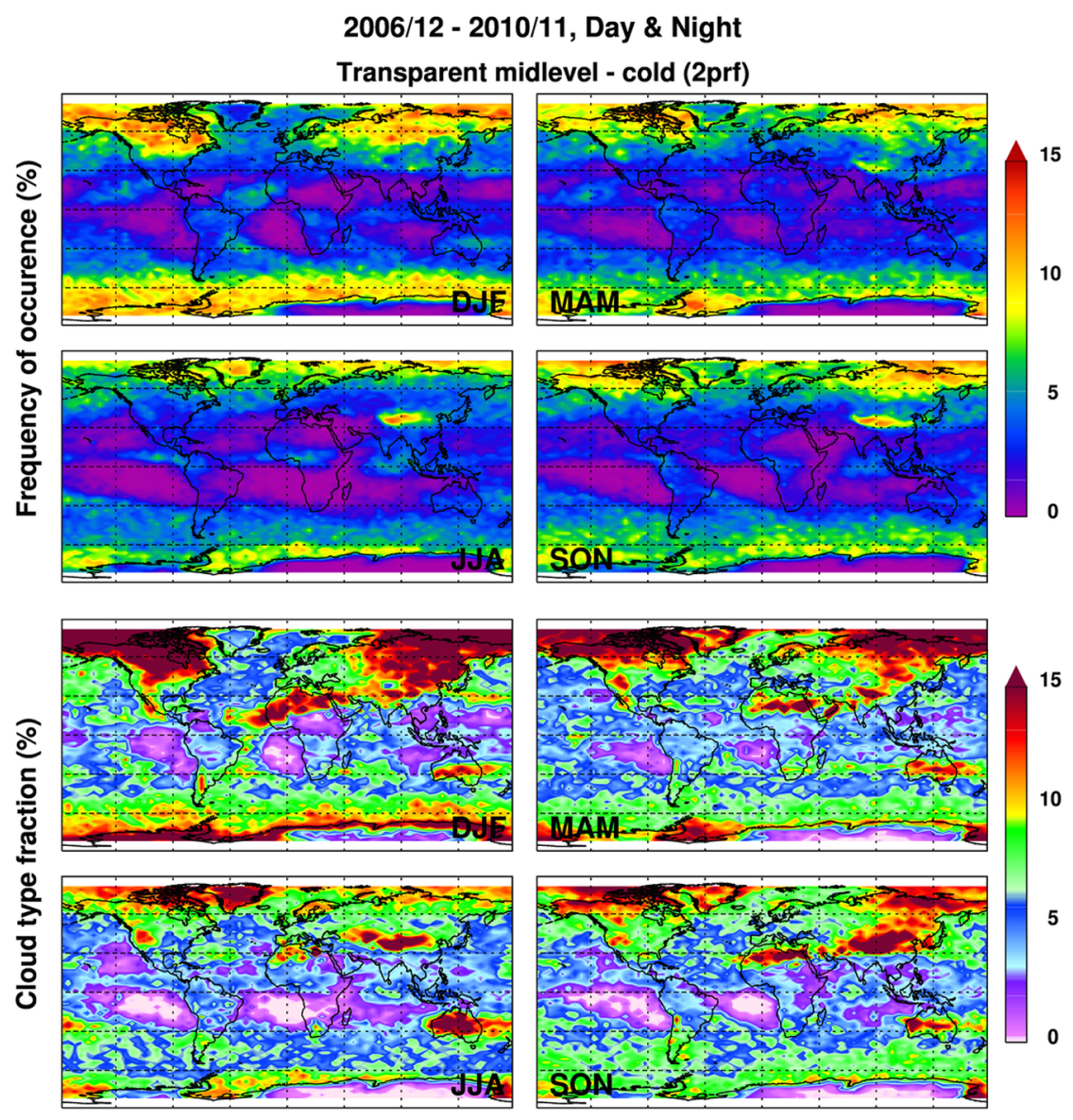

Fig. 5 Global seasonal variation in frequency of occurrence and cloud type fraction of M1 clouds at $10-\mathrm{km}$ resolution.

We show the zonally averaged frequency of occurrence of M1 clouds with altitude in Fig. 6. The M1 clouds occur at highest altitudes in the tropics and decrease in altitude toward the poles. The clouds are found at lowest altitudes in the wintertime at the poles. The clouds occur most often in the polar regions and least often in the subtropics. The occurrence of M1 clouds follows the atmospheric circulation, where the clouds are less common in the descending branch of the Hadley-cell in the subtropics. In the tropical regions, M1 clouds are found at altitudes of 7- to $10-\mathrm{km}$ altitude, while the tropopause level varies between 16 and $18 \mathrm{~km}$. This observation supports the view that tropical M1 clouds are formed through detrainment of convective towers that extend into the upper atmosphere. ${ }^{34,35}$

We tabulate the macrophysical properties of M1 clouds over different latitude regions in Table 3. Here, the relative occurrence is calculated as the ratio of M1 clouds that occur in each latitudinal belt to the global M1 cloud amounts. M1 clouds are more abundant in the northern hemisphere $(\sim 47 \%)$ than in the southern hemisphere $(\sim 38 \%)$ extratropics (poleward of $30^{\circ}$ ). As mentioned earlier, this may be related to the availability of ice nuclei for the M1 cloud formation. Further, the average M1 cloud thickness increases from tropical to polar regions in both hemispheres. The average M1 cloud thickness is higher in the Arctic $(1.4 \mathrm{~km})$ than any other region. This observation is consistent with the thin midlevel ice cloud climatology derived from ground-based lidar observations that reported average thin midlevel ice cloud thickness as $1.7 \mathrm{~km}$ over the sub-Arctic region. ${ }^{36}$

We highlight the occurrence of M1 clouds in the polar regions in Fig. 7. We see distinct seasonal asymmetry between the occurrence of these clouds in the Arctic and the Antarctic. These clouds occur most commonly in the wintertime (DJF) in the Arctic and the summertime (DJF) in the Antarctic. These clouds occur least commonly in the summertime (JJA) in the Arctic and the wintertime (JJA) in the Antarctic. We also see that the clouds occur more commonly over 


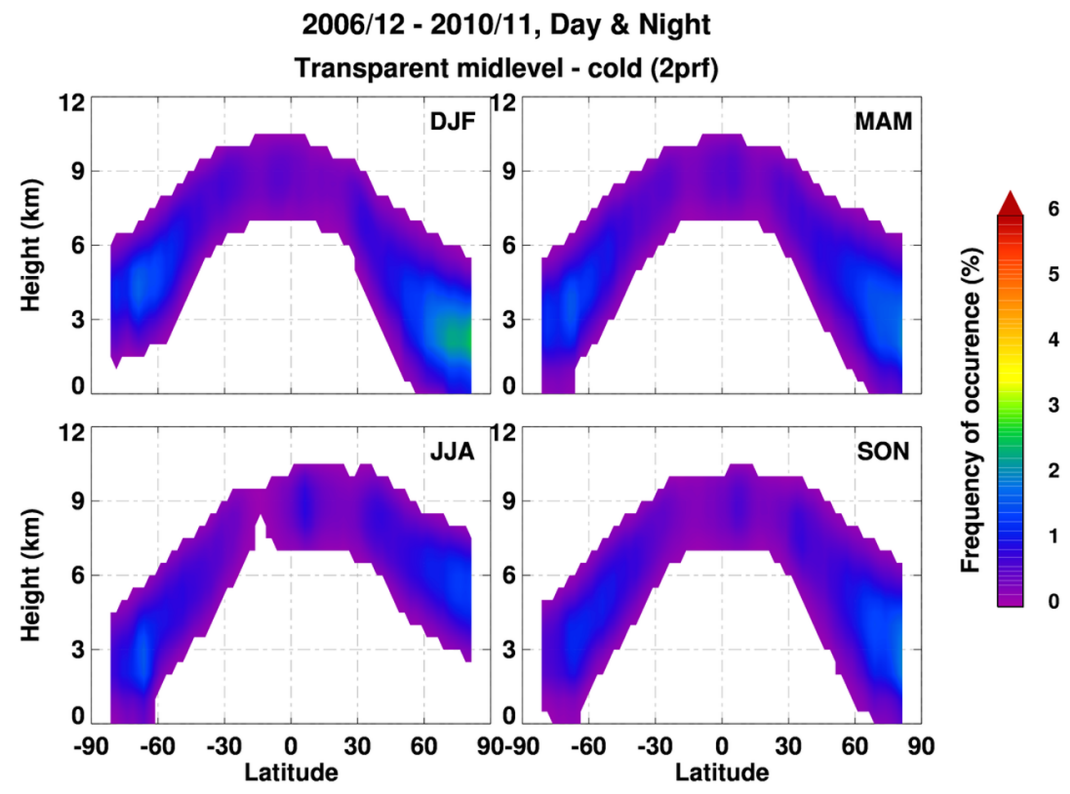

Fig. 6 Zonally averaged frequency of occurrence of M1 clouds plotted as a function of latitude and altitude.

Table 3 Macrophysical properties of M1 clouds observed by CALIPSO.

\begin{tabular}{|c|c|c|c|c|c|c|}
\hline \multirow{2}{*}{$\begin{array}{l}\text { Latitudinal } \\
\text { belt }\end{array}$} & \multicolumn{2}{|c|}{ Cloud top } & \multicolumn{2}{|c|}{ Cloud base } & \multirow{2}{*}{$\begin{array}{c}\text { Cloud } \\
\text { thickness } \\
(\mathrm{km})\end{array}$} & \multirow{2}{*}{$\begin{array}{c}\text { Relative } \\
\text { occurrence } \\
(\%)\end{array}$} \\
\hline & Height $(\mathrm{km})$ & Temperature $\left({ }^{\circ} \mathrm{C}\right)$ & Height $(\mathrm{km})$ & Temperature $\left({ }^{\circ} \mathrm{C}\right)$ & & \\
\hline $90 \mathrm{~N}-60 \mathrm{~N}$ & $4.6 \pm 0.3$ & $-27.6 \pm 0.5$ & $3.2 \pm 0.4$ & $-21.2 \pm 0.5$ & $1.4 \pm 0.1$ & 29 \\
\hline $60 N-30 N$ & $6.4 \pm 0.3$ & $-27.5 \pm 0.4$ & $5.2 \pm 0.3$ & $-20.8 \pm 0.3$ & $1.2 \pm 0.1$ & 18 \\
\hline $30 N-30 S$ & $8.8 \pm 0.1$ & $-26.5 \pm 0.5$ & $7.7 \pm 0.1$ & $-19.5 \pm 0.5$ & $1.0 \pm 0.1$ & 15 \\
\hline $60 S-30 S$ & $6.2 \pm 0.2$ & $-27.5 \pm 0.2$ & $5.1 \pm 0.2$ & $-20.1 \pm 0.2$ & $1.0 \pm 0.0$ & 18 \\
\hline 90S-60S & $4.2 \pm 0.2$ & $-28.8 \pm 0.5$ & $3.0 \pm 0.3$ & $-22.5 \pm 0.4$ & $1.2 \pm 0.0$ & 20 \\
\hline
\end{tabular}
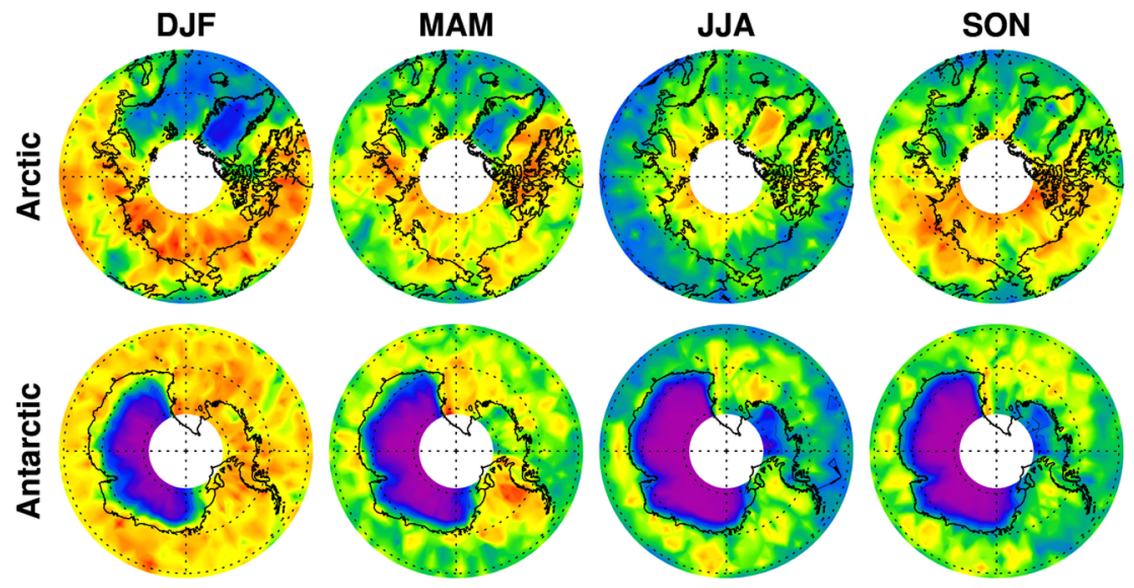

Frequency of occurrence (\%)

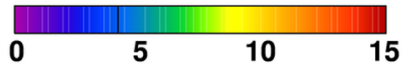

Fig. 7 Frequency of occurrence of M1 clouds as a function of season in the Arctic and the Antarctic. 
low altitudes than high altitudes, being less common over Greenland and the Antarctic plateau than the surrounding regions. The M1 clouds are less common over the North Atlantic, where M2 clouds are more common.

\section{Radiative Properties of M1 Ice Clouds}

To assess the radiative impact of M1 clouds, we employ an open source radiative transfer model that has been used to study midlevel clouds. ${ }^{21,37}$ We search the CALIPSO data set to find clouds that extend over more than $500 \mathrm{~km}$. We choose these large clouds to ensure that the clouds represent well-formed stable clouds, and that the scale of the clouds matches the scale of the accompanying meteorological reanalysis data.

\subsection{Radiative Transfer Model}

We use the library for radiative transfer (libRadtran) package to estimate the radiative properties of M1 clouds. ${ }^{38}$ LibRadtran is a software package designed to calculate the radiative quantities such as radiances, irradiances at user-defined altitudes within the atmosphere using input data of the extraterrestrial radiation, the atmosphere (pressure, temperature, humidity, $\mathrm{O}_{3}, \mathrm{~N}_{2}, \mathrm{O}$, and $\mathrm{CO}_{2}$ profiles), and surface properties. The complete details of the libRadtran model along with examples on how to run simulations are provided online. ${ }^{39}$ This package is publicly available and suitable for computing radiative effects of aerosols and clouds under user-defined boundary conditions. ${ }^{40}$ We use the meteorological data (i.e., pressure, temperature, relative humidity, and ozone number density) obtained from the CALIPSO data product as inputs to the model to represent the atmospheric conditions for the observed clouds. We choose the standard subarctic winter profiles for the atmospheric data above $30-\mathrm{km}$ altitude. ${ }^{41}$ The aerosol microphysical properties of maritime type for the winter season represent the background aerosol conditions for the simulations. At $1 \mu \mathrm{m}$, the maritime aerosol has an aerosol optical thickness of 0.11 and an angstrom exponent of $0.63 .{ }^{42}$ The surface spectral albedo plays a crucial role in the simulation of radiative transfer in the solar spectral range. The libRadtran software provides an option to input any measured surface albedo or to use a standard library of spectral albedo values. These standard values are taken from International Geosphere-Biosphere Program database that provides spectral albedo of these surface types derived from satellite measurements. ${ }^{43}$ However, for our simulations, we use a modified spectral albedo of the surface-type permanent ice/snow that we have validated with published studies. ${ }^{21,37}$ The simulations in the solar spectral range (290 to $4000 \mathrm{~nm}$ ) are performed with the discrete ordinate radiative transfer solver DISORT version 2.0. ${ }^{44}$ We use the extraterrestrial solar irradiance spectrum in the solar spectral range. ${ }^{45}$ We use the LOWTRAN band model from SBDART to account for the gaseous absorption. ${ }^{46}$ We use the two-stream radiative solver in the infrared range (4 to $100 \mu \mathrm{m}$ ). ${ }^{47}$

We estimate the cloud microphysical properties based on previous studies that reported in-situ measurements of optically thin midlevel clouds. ${ }^{20,21}$ These studies reported thin altocumulus clouds with small water droplets not exceeding $20 \mu \mathrm{m}$ in size and thin altostratus clouds consisting solely of ice particles (columns with rounded edges) with maximum size up to $100 \mu \mathrm{m}$. Further, the measured liquid/ice water content for these clouds was reported

Table 4 Distinct large-scale M1 clouds identified by CALIPSO.

\begin{tabular}{lllccc}
\hline \hline & \multicolumn{1}{c}{ Date } & \multicolumn{1}{c}{ Location } & Time (UTC) & $\begin{array}{c}\text { Mean solar } \\
\text { zenith angle (deg) }\end{array}$ & $\begin{array}{c}\text { Median } \\
\text { optical depth }\end{array}$ \\
\hline Case 1 & March 9, 2007 & Arctic Ocean & 1906 & 93 & 1.1 \\
Case 2 & March 10, 2007 & Chukchi Sea & 1456 & 102 & 0.8 \\
Case 3 & December 1, 2007 & Kara Sea coast & 0531 & 96 & 1.0 \\
Case 4 & December 6, 2007 & Baffin Bay & 0739 & 128 & 2.0 \\
Case 5 & February 14, 2009 & Beaufort Sea & 2021 & 85 & 0.6 \\
\hline \hline
\end{tabular}


Table 5 Characteristics of Arctic M1 clouds.

\begin{tabular}{|c|c|c|}
\hline & Range & Average \\
\hline \multicolumn{3}{|l|}{ Case 1: March 9, 2007} \\
\hline Optical depth & 0.2 to 5.4 & $1.4(1.1)$ \\
\hline Cloud top altitude (km) & 3.1 to 4.4 & 3.5 \\
\hline Cloud base altitude $(\mathrm{km})$ & 0.6 to 2.8 & 1.8 \\
\hline Cloud top temperature $\left({ }^{\circ} \mathrm{C}\right)$ & -35.2 to -28.0 & -30.0 \\
\hline Cloud base temperature $\left({ }^{\circ} \mathrm{C}\right)$ & -29.0 to -22.0 & -24.0 \\
\hline \multicolumn{3}{|l|}{ Case 2: March 10, 2007} \\
\hline Optical depth & 0.05 to 4.5 & $1.1(0.8)$ \\
\hline Cloud top altitude (km) & 3.6 to 5.0 & 4.4 \\
\hline Cloud base altitude (km) & 1.5 to 3.5 & 2.6 \\
\hline Cloud top temperature $\left({ }^{\circ} \mathrm{C}\right)$ & -37.0 to -28.6 & -34.0 \\
\hline Cloud base temperature $\left({ }^{\circ} \mathrm{C}\right)$ & -29.4 to -22.0 & -24.6 \\
\hline \multicolumn{3}{|l|}{ Case 3: December 1, 2007} \\
\hline Optical depth & 0.05 to 6.0 & $1.1(1.0)$ \\
\hline Cloud top altitude (km) & 2.8 to 5.3 & 4.4 \\
\hline Cloud base altitude (km) & 0.2 to 3.8 & 1.4 \\
\hline Cloud top temperature $\left({ }^{\circ} \mathrm{C}\right)$ & -33.0 to -20.8 & -28.6 \\
\hline Cloud base temperature $\left({ }^{\circ} \mathrm{C}\right)$ & -29.0 to -13.0 & -18.0 \\
\hline \multicolumn{3}{|l|}{ Case 4: December 6, 2007} \\
\hline Optical depth & 0.4 to 6.0 & $2.0(2.0)$ \\
\hline Cloud top altitude (km) & 2.3 to 3.7 & 3.0 \\
\hline Cloud base altitude $(\mathrm{km})$ & 0.1 to 2.8 & 1.4 \\
\hline Cloud top temperature $\left({ }^{\circ} \mathrm{C}\right)$ & -35.0 to -27.0 & -32.3 \\
\hline Cloud base temperature $\left({ }^{\circ} \mathrm{C}\right)$ & -32.0 to -14.4 & -24.4 \\
\hline \multicolumn{3}{|l|}{ Case 5: February 14, 2009} \\
\hline Optical depth & 0.6 to 4.0 & $1.0(0.6)$ \\
\hline Cloud top altitude (km) & 3.1 to 5.8 & 5.0 \\
\hline Cloud base altitude (km) & 2.6 to 5.2 & 3.4 \\
\hline Cloud top temperature $\left({ }^{\circ} \mathrm{C}\right)$ & -33.0 to -21.4 & -27.0 \\
\hline Cloud base temperature $\left({ }^{\circ} \mathrm{C}\right)$ & -30.0 to -19.0 & -22.3 \\
\hline
\end{tabular}

to have an average value of $0.01 \mathrm{~g} \mathrm{~m}^{-3}$ with a maximum value of $0.45 \mathrm{~g} \mathrm{~m}^{-3}$. With this information, we have chosen effective radii of 30 and $60 \mu \mathrm{m}$ for ice clouds and 10 and $20 \mu \mathrm{m}$ for water clouds, respectively. For the case of mixed phase clouds, we choose clouds composed of 20- $\mu \mathrm{m}$ water drops and $60-\mu \mathrm{m}$ ice columns and then consider four cases where the ice fraction of the total optical depth is $20 \%, 40 \%, 60 \%$, and $80 \%$. We have performed radiative transfer simulations using these eight scenarios of microphysical properties and the cloud altitudes and optical depths derived from CALIPSO data. 
Table 6 Radiative impact of M1 clouds.

\begin{tabular}{llccc}
\hline \hline & Date & $\begin{array}{c}\text { Clear sky net LW } \\
\text { irradiance }\left(\mathrm{W} / \mathrm{m}^{2}\right)\end{array}$ & $\begin{array}{c}\text { Cloud net LW } \\
\text { irradiance }\left(\mathrm{W} / \mathrm{m}^{2}\right)\end{array}$ & $\begin{array}{c}\text { Cloud LW radiative } \\
\text { forcing }\left(\mathrm{W} / \mathrm{m}^{2}\right)\end{array}$ \\
\hline Case 1 & March 9, 2007 & -55 & $-12 \pm 1$ & $43 \pm 1$ \\
Case 2 & March 10, 2007 & -61 & $-29 \pm 1$ & $32 \pm 1$ \\
Case 3 & December 1, 2007 & -75 & $-36 \pm 1$ & $39 \pm 1$ \\
Case 4 & December 6, 2007 & -81 & $-33 \pm 1$ & $48 \pm 1$ \\
Case 5 & February 14, 2009 & -75 & $-45 \pm 1$ & $30 \pm 1$ \\
\hline & & Clear sky net SW & Cloud net SW & Cloud SW radiative \\
& & irradiance $\left(\mathrm{W} / \mathrm{m}^{2}\right)$ & irradiance $\left(\mathrm{W} / \mathrm{m}^{2}\right)$ & forcing $\left(\mathrm{W} / \mathrm{m}^{2}\right)$ \\
\hline Case 5 & February 14, 2009 & 24 & 17 & -7 \\
\hline \hline
\end{tabular}

\subsection{Results of Case Studies}

We find five large M1 clouds that each extended over $500 \mathrm{~km}$. These five clouds are all found in the Arctic and we tabulate their locations, solar zenith angle, and optical depth in Table 4. Of these five clouds, four are observed when the sun was below the horizon and one, case 5, is observed when the sun was just above the horizon. We cite the median optical depth rather than the mean value, as the median is more representative of the whole cloud. The mean values are higher than the median values and reflect the influence of a few high values. We tabulate the range and average of the optical depth, cloud top altitude, cloud base altitude, cloud top temperature, and cloud base temperature in Table 5. The median value of the optical depth is presented in parenthesis next to the average value. The synoptic meteorological conditions for these days show that these clouds are formed along the frontal zones with weakly ascending air masses. ${ }^{48}$

For each of these five cases, we calculate the cloud radiative forcing (CRF) as the difference between the net downward irradiance under cloudy and clear sky conditions. A positive value of the CRF indicates that the cloud has a warming effect on the surface. For example in case 1, the clear sky has a net longwave (LW) irradiance of $-55 \mathrm{~W} / \mathrm{m}^{2}$ indicating cooling. In case 1 , with the M1 cloud present, the net irradiance is $-12 \pm 1 \mathrm{~W} / \mathrm{m}^{2}$. The value of $-12 \mathrm{~W} / \mathrm{m}^{2}$ with an uncertainty of $1 \mathrm{~W} / \mathrm{m}^{2}$ is the average and standard deviation in the values determined from the eight cloud scenarios. The small standard deviation reflects the fact that the different microphysical characteristics have little effect on the radiative properties of these thin clouds. Thus, in case 1 , we estimate that the M1 has a CRF of $43 \pm 1 \mathrm{~W} / \mathrm{m}^{2}$ and a net warming effect on the surface. We tabulate our results for all five case studies in Table 6 . We estimate the LW radiative forcing for all cases and the shortwave (SW) forcing for case 5, where the cloud is illuminated by the sun. We find that the LW CRF is positive in all cases with values ranging between 28 and $48 \mathrm{~W} / \mathrm{m}^{2}$, with a mean value of $36 \mathrm{~W} / \mathrm{m}^{2}$. We conclude that M1 cloud has a net warming effect in the LW. In case 5, we see that the cloud has an SW CRF of $-7 \mathrm{~W} / \mathrm{m}^{2}$ indicating that the cloud has a net cooling effect in the SW. However, the combined SW and LW effect of the cloud is to yield a CRF of $23 \mathrm{~W} / \mathrm{m}^{2}$, indicating a net warming. To further explore the balance of SW and LW radiative forcing, we conducted the CRF when changing the solar zenith angle from $85 \mathrm{deg}$ to $80 \mathrm{deg}$ and $70 \mathrm{deg}$. While the LW warming effect of the cloud remains constant, the SW cooling effect increases and the total CRF reduces to $10 \mathrm{~W} / \mathrm{m}^{2}$ at $80 \mathrm{deg}$ and to $-6 \mathrm{~W} / \mathrm{m}^{2}$ at $70 \mathrm{deg}$.

\section{Summary and Conclusions}

In this study, we have used logic-based rules to categorize midlevel clouds as M1 (optically thin and ice dominated), M2 (optically thin and water dominated), and M3 (optically thick) cloud types. We find that the ice-dominated M1 clouds occur most commonly over the polar regions. The water-dominated M2 clouds occur most commonly over the tropics. The thicker M3 clouds 
occur most commonly in the tropics, midlatitudes over eastern Asia and Pacific Ocean, and subpolar regions. The global distributions of M1 and M2 clouds are similar to the distributions of altostratus and altocumulus clouds, respectively. ${ }^{23}$ The global distribution of M3 clouds is also similar to that of midlevel liquid-layer topped stratiform clouds. ${ }^{22}$

The global mean occurrence of M1 clouds is $4.5 \%$ and represents $7.3 \%$ of all tropospheric clouds detected by CALIPSO. This estimate of M1 cloud occurrence is a lower bound as optically thicker H3 and M3 clouds can obscure M1 clouds from CALIPSO. During Arctic midwinter, M1 clouds occur up to $15 \%$ of the time. In both the Arctic and the Antarctic, M1 clouds occur most commonly during December to January to February, indicating no seasonal hemispheric symmetry in the occurrence of these clouds. The low amount of M1 cloud cover over Antarctica in winter is consistent with the extremely low temperatures, low humidity, and the ice-sheets steep coastal slopes blocking advection from lower latitudes. ${ }^{49}$ In the Arctic, the M1 clouds occur least over Greenland in winter and spring, again consistent with very low temperatures and low humidity over Greenland. ${ }^{50} \mathrm{M} 1$ cloud occurrences are also lower along major storm tracks, indicating they form under relatively stable conditions that would otherwise allow the cloud particles to grow large sizes and eventually precipitate. A high fraction of M1 clouds is observed over arid regions of Africa, Asia, and Australia suggesting that dust particles may form as ice nuclei that trigger the formation of M1 clouds. ${ }^{32}$ The horizontal scales for these clouds show that up to $50 \%$ of these cloud population form with sizes of less than $25 \mathrm{~km}$ and resemble typical thin altocumulus clouds forming under mesoscale weather processes.

While the majority of M1 clouds occur at smaller scales of $25 \mathrm{~km}$, the extensive CALIPSO observations allowed us find five large clouds that extended over $500 \mathrm{~km}$. We analyzed these large M1 clouds and found that they have a cloud LW radiative forcing of $36 \mathrm{~W} / \mathrm{m}^{2}$. This indicates that M1 clouds have a significant warming effect during the Arctic winter. Four of these clouds occurred at night and one occurred in daylight. Analysis of the cloud in daylight indicated that the combined SW and LW radiative forcing decreases as the solar zenith angle reduces, decreasing from $23 \mathrm{~W} / \mathrm{m}^{2}$ at a solar zenith angle of $85 \mathrm{deg}$ to $-6 \mathrm{~W} / \mathrm{m}^{2}$ at a solar zenith angle of $70 \mathrm{deg}$, and indicates that M1 clouds have a net cooling effect during the Arctic summer.

Our current study has documented thin midlevel ice clouds. The use of satellite-based active remote sensing techniques is critical in identifying these clouds. Optically thin and thick midlevel clouds should be treated separately to better understand their impacts on the Earth's radiation budget.

\section{Acknowledgments}

The authors thank the Arctic Facility for Atmospheric Remote Sensing, CALIPSO, and the libRadTran Science Teams for their support. The authors thank Kenneth Sassen for helpful discussions. This work was conducted with support from the National Science Foundation under Grant No. AGS 1037000. V.K.K. acknowledges support from the University of Alaska Fairbanks Graduate School for completion of this study. The authors thank two anonymous reviewers for their comments that led to improvements in this paper.

\section{References}

1. P. Minnis et al., "Estimating the top altitude of optically thick ice clouds from thermal infrared satellite observations using CALIPSO data," Geophys. Res. Lett. 35(12), L12801 (2008).

2. D. L. Hartmann and D. Doelling, "On the net radiative effectiveness of clouds," J. Geophys. Res. Atmos. 96(D1), 869-891 (1991).

3. D. L. Hartmann, M. E. Ockertbell, and M. L. Michelsen, "The effect of cloud type on earths energy balance—global analysis," J. Clim. 5(11), 1281-1304 (1992).

4. WMO, "Manual of codes, Vol. I," WMO Publication Vol. 306, World Meteorological Organization, Geneva (1988).

5. WMO, "International cloud atlas I and II," World Meteorological Organization, Geneva (1987).

6. S. G. Warren et al., "Global distribution of total cloud cover and cloud type amounts over the land," Vol. 29, NCAR Technical Note (1986). 
7. S. G. Warren et al., "Global distribution of total cloud cover and cloud type amounts over the ocean," Vol. 41, NCAR Technical Note (1988).

8. W. B. Rossow and R. A. Schiffer, "Advances in understanding clouds from ISCCP," Bull. Am. Meteorol. Soc. 80(11), 2261-2287 (1999).

9. L. D. Riihimaki, S. A. McFarlane, and J. M. Comstock, "Climatology and formation of tropical midlevel clouds at the Darwin ARM site," J. Clim. 25(19), 6835-6850 (2012).

10. A. Ansmann et al., "Evolution of the ice phase in tropical altocumulus: SAMUM lidar observations over Cape Verde," J. Geophys. Res. Atmos. 114(D17208), 1-20 (2009).

11. K. Yasunaga et al., "Melting layer cloud observed during R/V Mirai cruise MR01-K05," J. Atmos. Sci. 63(11), 3020-3032 (2006).

12. R. P. Fleishauer, V. E. Larson, and T. H. Vonder Haar, "Observed microphysical structure of midlevel, mixed-phase clouds," J. Atmos. Sci. 59(11), 1779-1804 (2002).

13. A. Korolev and G. Isaac, "Phase transformation of mixed-phase clouds," Q. J. R. Meteorol. Soc. 129(587), 19-38 (2003).

14. A. J. Smith et al., "Processes that generate and deplete liquid water and snow in thin midlevel mixed-phase clouds," J. Geophys. Res. Atmos. 114(D12203), 1-18 (2009).

15. M. D. Shupe, S. Y. Matrosov, and T. Uttal, "Arctic mixed-phase cloud properties derived from surface-based sensors at SHEBA," J. Atmos. Sci. 63(2), 697-711 (2006).

16. M. D. Shupe et al., "A focus on mixed-phase clouds: the status of ground-based observational methods," Bull. Am. Meteorol. Soc. 89(10), 1549-1562 (2008).

17. G. de Boer, E. W. Eloranta, and M. D. Shupe, "Arctic mixed-phase stratiform cloud properties from multiple years of surface-based measurements at two high-latitude locations," J. Atmos. Sci. 66(9), 2874-2887 (2009).

18. M. H. Zhang et al., "Comparing clouds and their seasonal variations in 10 atmospheric general circulation models with satellite measurements," J. Geophys. Res. Atmos. 110(D15S02), 1-18 (2005).

19. A. J. Illingworth et al., "Cloudnet — continuous evaluation of cloud profiles in seven operational models using ground-based observations," Bull. Am. Meteorol. Soc. 88(6), 883-898 (2007).

20. P. V. Hobbs and A. L. Rangno, "Microstructures of low and middle-level clouds over the Beaufort Sea," Q. J. R. Meteorol. Soc. 124(550), 2035-2071 (1998).

21. A. Lampert et al., "Microphysical and radiative characterization of a subvisible midlevel Arctic ice cloud by airborne observations-a case study," Atmos. Chem. Phys. 9(8), 2647-2661 (2009).

22. D. M. Zhang, Z. Wang, and D. Liu, "A global view of midlevel liquid-layer topped stratiform cloud distribution and phase partition from CALIPSO and CloudSat measurements," J. Geophys. Res. Atmos. 115(D00H13), 1-10 (2010).

23. K. Sassen and Z. Wang, "The clouds of the middle troposphere: composition, radiative impact, and global distribution," Surv. Geophys. 33(3-4), 677-691 (2012).

24. D. Winker, J. Pelon, and M. P. Mccormick, "The CALIPSO mission: spaceborne lidar for observation of clouds and aerosols," Proc. SPIE 4893, 1-11 (2003).

25. M. A. Vaughan, D. M. Winker, and K. A. Powell, "CALIOP algorithm theoretical basic document: part 2-feature detection and layer properties algorithms," in PC-SCI-202.02, NASA Langely Research Center, Hampton, Virginia (2005).

26. K. Sassen and G. C. Dodd, "Homogeneous nucleation rate for highly supercooled cirrus cloud droplets," J. Atmos. Sci. 45(8), 1357-1369 (1988).

27. H. Pruppacher and J. Klett, Microphysics of Clouds and Precipitation, 2nd ed., Springer, New York (1997).

28. D. Rosenfeld and W. L. Woodley, "Deep convective clouds with sustained supercooled liquid water down to-37.5 degrees C," Nature 405(6785), 440-442 (2000).

29. K. Sassen, "Cirrus clouds: a modern perspective," in Cirrus, D. K. Lynch et al., Eds., pp. 11-40, Oxford University Press, New York (2002).

30. T. Morris and R. R. Braham, "The occurrence of ice particles in Minnesota cumuli," presented at Proc. of Weather Modification, American Meteorological Society, pp. 306-315 (1968). 
31. K. Sassen and Z. Wang, "Classifying clouds around the globe with the CloudSat radar: 1-year of results," Geophys. Res. Lett. 35(L04805), 1-5 (2008).

32. K. Sassen, "Dusty ice clouds over Alaska," Nature 434(7032), 456-456 (2005).

33. K. Sassen and V. I. Khvorostyanov, "Cloud effects from boreal forest fire smoke: evidence for ice nucleation from polarization lidar data and cloud model simulations," Environ. Res. Lett. 3(025006), 1-12 (2008).

34. I. Folkins, S. J. Oltmans, and A. M. Thompson, "Tropical convective outflow and near surface equivalent potential temperatures," Geophys. Res. Lett. 27(16), 2549-2552 (2000).

35. P. Seifert et al., "Saharan dust and heterogeneous ice formation: eleven years of cloud observations at a central European EARLINET site," J. Geophys. Res. Atmos. 115(D20201), $1-13(2010)$.

36. V. K. Kayetha, "Ice clouds over Fairbanks, Alaska," MS Thesis, University of Alaska Fairbanks (2014).

37. E. Andre, "The impact of ice crystals on radiative forcing and remote sensing of Arctic boundary-layer mixed-phase clouds," PhD Dissertation, Johannes Gutenberg-Universitat Mainz, Germany (2009).

38. B. Mayer and A. Kylling, "Technical note: the libRadtran software package for radiative transfer calculations-description and examples of use," Atmos. Chem. Phys. 5, 1855-1877 (2005).

39. B. Mayer et al., "DownloadlLibradtran," 2008, http://www.libradtran.org/doku.php? id=download (1 June 2015).

40. B. Mayer et al., "Start|Libradtran," 2008, http://www.libradtran.org (1 June 2015).

41. G. Anderson et al., "AFGL atmospheric constituent profiles $(0-120 \mathrm{~km})$," Technical Report AFGL-TR-86-0110 (1986).

42. E. Shettle, "Models of aerosols, clouds and precipitation for atmospheric propagation studies," presented at AGARD Conf. Proc. No. 454, Atmospheric Propagation in the UV, Visible, IR and MM-Region and Related Systems Aspects, pp. 1-359 (1989).

43. A. Belward and T. Loveland, "The DIS $1 \mathrm{~km}$ land cover data set," Global Change Newsletter 27, 7-9 (1996).

44. K. Stamnes et al., "Numerically stable algorithm for discrete-ordinate method radiative transfer in multiple scattering and emitting layered media," Appl. Opt. 27(12), 2502-2509 (1988).

45. C. A. Gueymard, "The sun's total and spectral irradiance for solar energy applications and solar radiation models," Sol. Energy 76(4), 423-453 (2004).

46. P. Ricchiazzi et al., "SBDART: a research and teaching software tool for plane-parallel radiative transfer in the Earth's atmosphere," Bull. Am. Meteorol. Soc. 79(10), 2101-2114 (1998).

47. A. Kylling, K. Stamnes, and S. C. Tsay, "A reliable and efficient 2-stream algorithm for spherical radiative transfer-documentation of accuracy in realistic layered media," J. Atmos. Chem. 21(2), 115-150 (1995).

48. V. K. Kayetha, "Investigation of thin midlevel ice clouds in the Arctic using CALIPSO data and radiative transfer modeling," PhD Dissertation, University of Alaska Fairbanks (2015).

49. D. H. Bromwich et al., "Tropospheric clouds in Antarctica," Rev. Geophys. 50, RG1004 (2012).

50. M. D. Shupe et al., "High and dry: new observations of tropospheric and cloud properties above the Greenland Ice Sheet," Bull. Am. Meteor. Soc. 94, 169-186 (2013).

Vinay K. Kayetha received his PhD from the Department of Atmospheric Sciences, University of Alaska Fairbanks, USA. Currently, he is a research scientist at Science Systems and Applications Inc., Maryland. His current research includes developing remote sensing retrievals of cloud of aerosol properties and radiative transfer modeling.

Richard L. Collins received his $\mathrm{PhD}$ from the Department of Electrical and Computer Engineering, University of Illinois, Urbana-Champaign, USA. Currently, he is a professor at the Geophysical Institute and Department of Atmospheric Sciences at the University of Alaska Fairbanks. His current research includes remote sensing and the weather and climate of the middle atmosphere. He maintains an active lidar research program at the Poker Flat Research Range, Alaska. 